\title{
RNAi and microRNA: breakthrough technologies for the improvement of plant nutritional value and metabolic engineering
}

\author{
Guiliang Tang · Gad Galili $\cdot$ Xun Zhuang
}

Received: 6 February 2007/Accepted: 29 June 2007/Published online: 2 September 2007

(C) Springer Science+Business Media, LLC 2007

\begin{abstract}
This article raises the complex issue of improving plant nutritional value through metabolic engineering and the potential of using RNAi and micro RNA technologies to overcome this complexity, focusing on a few key examples. It also highlights current knowledge of RNAi and microRNA functions and discusses recent progress in the development of new RNAi vectors and their applications. RNA interference (RNAi) and microRNA (miRNA) are recent breakthrough discoveries in the life sciences recognized by the 2006 Nobel Prize in Physiology or Medicine. The importance of these discoveries relates not only to elucidating the fundamental regulatory aspects of gene expression, but also to the tremendous potential of their applications in plants and animals. Here, we review recent applications of RNAi and microRNA for improving the nutritional value of plants, discuss applications of metabolomics technologies in genetic engineering, and provide an update on the related RNAi and microRNA technologies.
\end{abstract}

Keywords RNAi - siRNA - miRNA - RNAi vector . Antisense $\cdot$ Co-suppression · Gene disruption · Silencing suppressor · Nutrition · Essential amino acids . Metabolomics

G. Tang $(\bowtie) \cdot X$. Zhuang

Gene Suppression Laboratory, Department of Plant and Soil Science \& KTRDC, University of Kentucky, Lexington, KY 40546-0236, USA

e-mail: guiliang.tang@uky.edu

G. Galili

Department of Plant Science, The Weizmann Institute of Science, Rehovot 76100, Israel

\section{Introduction}

Traditional breeding has been tremendously successful in improving the nutritional value of food and feed (Davies 2003). However, this process is time-consuming, and the limited genetic resources of most crops have left little room for continued improvement by these means. There are many reasons for the limited genetic resources available for breeding (Hoisington et al. 1999). Two of the most important ones are: (i) loss of gene pools occurring during the domestication and breeding of crop plants (Lee 1998); and (ii) many of the natural gene traits that may be beneficial in one plant tissue, such as seeds and fruits, may be deleterious in other plant tissues such as vegetative tissues (for example see below) (Frankard et al. 1992; Negrutiu et al. 1984; Zhu and Galili 2003). Over the past few decades, breeding possibilities have been broadened by genetic engineering and gene transfer technologies, as well as by gene mapping and identification of the genome sequences of model plants and crops. Directed efforts are now underway to use genetic engineering of metabolic pathways to alter plant nutrient levels (Galili et al. 2002). These efforts depend on a detailed understanding of plant metabolic pathways and constituent enzymes as well as on regulatory genes that control these enzymes.

Opportunities and challenges in metabolic engineering of secondary metabolic pathways have been extensively reviewed in recent years (Facchini et al. 2000; Hughes and Shanks 2002; Kutchan 2005; Trethewey 2004). Modern technologies such as trancriptomics, proteomics, and metabolomics are now proving to be important in understanding plant metabolic pathways and the role of key genes associated with their regulation. Metabolomics may offer particular advantages in understanding of metabolic networks and their regulation (Hollywood et al. 2006). Key 
technologies in metabolomics, particularly mass spectrometry (MS) and gas chromatography interfaced with mass spectrometry (GC-MS) (Villas-Boas et al. 2005) allow the rapid discovery of the most influential step in a target pathway and the metabolic impact of modifying that pathway. This can facilitate new insights into the complex metabolite neighborhoods that give rise to a given phenotype and may allow discovery of new target genes to modify a given pathway. Such genes can then be subject to new metabolic engineering efforts and applications. The reader is referred to both Larkin and Harrigan (2007) and Wakasa et al. (2007) for examples of the application of metabolic profiling to studying a diverse range of transgenically modified plants.

It should also be added that, metabolomics-related technologies such as stable isotope-base based dynamic metabolic profiling (SIDMAP) or mass isotopomer analysis (MIA) (Bederman et al. 2004b; Boros 2005) may also prove extremely useful in pathway discoveries. These fluxbased approaches are less used than compositional analyses but hold significant promise (see Ratcliffe and SchacharHill 2006).

Currently, the major strategy for transgenic enhancement of plant nutrient levels involves increasing the levels of expression of anabolic biosynthetic genes. Unfortunately, the efficacy of this approach for crop engineering has been restricted by two main obstructions. First, the introduction of extra gene copies can have the non-intuitive effect of decreasing expression from the introduced and homologous endogenous loci, a phenomenon of gene silencing known as "co-suppression" (Napoli et al. 1990; van der Krol et al. 1990). Second, feedback metabolic loops tend to maintain homeostatic nutrient levels. For example, plants might respond to increased nutrient production induced by overexpression of biosynthetic genes by activating a degradation pathway that either negates nutrient accumulation or converts nutrients into undesirable metabolites (Karchi et al. 1994). Therefore, it is also necessary to consider schemes for metabolic engineering that involve decreasing the levels of catabolic enzymes. Similar schemes could also be used to decrease the levels of antinutritional compounds. Effective and expedient methods to decrease gene expression, however, are currently under-developed.

Ironically, the very phenomenon of co-suppression that plagues certain overexpression efforts might be generally useful for decreasing gene expression. Co-suppression has recently been recognized as a manifestation of RNA interference (RNAi), an endogenous pathway for negative post-transcriptional regulation. RNAi has revolutionized the possibilities for creating custom "knock-downs" of gene activity. RNAi operates in both plants and animals, and uses double stranded (dsRNA) as a trigger that targets homologous mRNAs for degradation. Methods that introduce dsRNA into plant and animal cells have been enormously successful for decreasing cognate gene expression in vivo (Hannon 2002; Shi 2003; Vaucheret et al. 2001; Zamore 2001). In this article, we briefly describe "omics", particularly metabolomics, as technical approaches to gene discovery and metabolic pathway modification. We then introduce current knowledge of the endogenous RNAi pathways in plants, and discuss strategies and applications of RNAi for the improvement of plant nutritional value via a coordinated overexpression and suppression of genes in plants. Finally, we look into the development of new plant RNAi technologies.

\section{Gene discovery, metabolic pathway modification and metabolomics}

Metabolic engineering largely depends on a deep understanding of target pathways and their associated genes, regulatory proteins and enzymes. In other words, gene, protein, or pathway discoveries represent the first steps in metabolic engineering (Fig. 1). In addition to genomics and whole genome sequencing, this can be achieved through technologies in three emerging areas, transcriptomics, proteomics, and metabolomics.

Several microarray platforms have been extensively adopted in transcriptomics experiments. These highthroughput technical approaches have not only revealed important protein-coding genes in metabolic pathways, but have also helped discover many non-protein coding genes that can be transcribed to produce a large population of endogenous small RNAs, or microRNAs (miRNAs). It is now known that these small RNAs are key players in the down regulation of protein-coding gene expression at the post-transcriptional level. Many genes targeted for down regulation by small RNAs include those encoding transcription factors that control many metabolic pathways including those implicated in developmental processes. Remarkably, it now turns out that about one third of human genes are under control by these small RNAs (Lewis et al. 2005; Xie et al. 2005). The discovery of the miRNA transcriptome and the mechanisms of gene regulation by these small RNAs have now allowed the evolution of important gene silencing approaches for genetic engineering (for details see below).

Similarly, technical approaches in proteomics, such as 2-D gel electrophoresis or mass spectrometry, are powerful in identifying the products of gene expression. In addition, proteomics can identify protein-protein interactions that are necessary for effective functioning of specific signaling pathways and thereby help to identify the genes that encode protein "partners". Modification of such genes may therefore lead to alterations in specific signaling pathways 


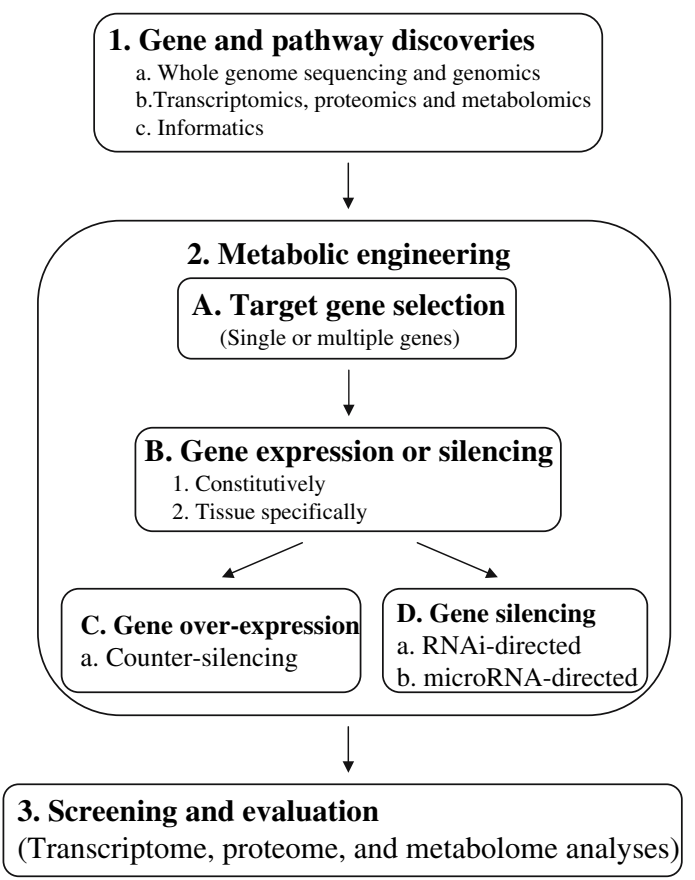

Fig. 1 Technologies used for metabolic engineering. The first step to metabolic engineering is to identify target pathways and their constituent genes through "omics" technologies including direct genome sequencing, genomics, transcriptome, proteome, and metabolome analyses. Informatics will be tightly integrated into various "omics" analyses. The second step is to select the target genes in the pathways for engineering. These genes can be those encoding ratecommitted, master transcription factor, or branch-directed protein or enzymes. The selected genes will be expressed or silenced individually or simultaneously, constitutively or tissue specifically. RNAi and microRNA technologies will be used in this step to silence unwanted genes. Counter-silencing technologies will be used to overexpress specific genes. Lastly, the impact of the engineered genes will be evaluated again using the "omics" technologies. The engineered, useful plants will be screened and used for various purposes

and serve as a basis for metabolic engineering strategies. It can therefore be reasoned that, proteomics may be more functionally revealing than transcriptomics.

Whole genome sequencing has pointed to the presence of many genes or proteins with unknown or hypothetical function. Metabolomics has been suggested as a key technology for functional analyses, including pathway discoveries and or genotype-phenotype associations (Fiehn et al. 2000; Fiehn 2002; Hall 2006). The term metabolome was first used in 1998 (Oliver et al. 1998) and has now been used to describe the complete set of small-molecule metabolites (metabolic intermediates, hormones, signaling molecules, and many other secondary metabolites) to be found within a biological sample of a single organism. As with the transcriptome and proteome, the metabolome is dynamic. It is further characterized by physicochemically divergent metabolites representing extraordinary ranges in natural abundances. Consequently, no single analytical method could possibly analyze the entire range of metabolites. The array of analytical techniques adopted in metabolomics experiments include gas chromatography-mass spectrometry (GC-MS; Fiehn et al. 2000), 2-dimensional GC coupled to MS (GCXGC-MS; Welthagen et al. 2005), liquid chromatography using an electrochemical array (LCEC; Gamache et al. 2004), high performance LC-MS (HPLC-MS; Buchholz et al. 2001), ultra performance LCMS (UPLC-MS; Wilson et al. 2005), hydrophobic interaction chromatography (HILIC; Tolstikov et al. 2003), capillary electrophoresis-MS (CE-MS; Soga et al. 2002), nuclear magnetic resonance (NMR; Nicholson et al. 1999), LC coupled to NMR (LC-NMR; Raamsdonk et al. 2001), fourier transform infrared spectroscopy (FT-IR; Harrigan et al. 2004), direct infusion ESI MS (DIMS; Vaidyanathan et al. 2002), laser desorption ionisation MS (LDI-MS; Vaidyanathan et al. 2005), fourier transform ion cyclotron resonance MS (FT-ICR-MS; Aharoni et al. 2002), stable isotope-based dynamic metabolic profiling or mass isotopomer analysis (Bederman et al. 2004a).

The technical approach adopted will depend on the specific biological question at hand but it is clear that metabolomics complements transcriptomics and proteomics and may even offer potential advantages. First, metabolomics is the study of events more downstream than that investigated by transcriptomics and proteomics. It is more related to pathway networks and closer to multi-gene controlled phenotype and may reveal gene networks that control an entire pathway. Second, metabolic fluxes are regulated not only by gene expression, but also by posttranscriptional or post-translational events (ter Kuile and Westerhoff 2001). Thus metablomics may uncover novel post-transcriptional or translational regulatory mechanisms for metabolic engineering. Finally, data from metabolomics analyses are increasingly well integrated with new informatics approaches to extract maximum value and generate new knowledge (Goodacre et al. 2004; Weckwerth and Morgenthal 2005). In summary, metabolomics is becoming an essential approach for functional analyses of metabolic pathways and their associated genetic networks. In combination with genomics, transcriptomics, and proteomics, it will have great potential in facilitating the development of the newly emerging technologies of genetic engineering including small RNA applications.

\section{RNAi and microRNA: ancient gene silencing pathways revealed in plants}

In the last decade, the completion of the sequencing of several plant genomes has brought about a new emphasis on genetic strategies for improving plant nutritional value. With improved genetic transformation technologies, plant 
scientists came to believe that they could produce any gene product by expressing the specific genes in plants. Unfortunately, this was not always the case. The phenomenon of plant co-suppression was accidentally discovered during attempts to alter the pigmentation of commercial petunia flowers using a genetic transformation approach (Napoli et al. 1990). It was presumed that deeper flower colors might be the result of overexpression of a chalcone synthase gene driven by the constitutive $35 \mathrm{~S}$ promoter. Instead, both endogenous and transgenic chalcone synthase genes were silenced in these plants, resulting in mosaic flowers with unpigmented white sectors (Napoli et al. 1990).

Eight years later, Andrew Fire and Craig Mello found that traces of dsRNA in Caenorhabditis elegans triggered a dramatic silencing of genes containing identical sequences to the dsRNA (Fire et al. 1998; Montgomery and Fire 1998; Tabara et al. 1998). They named this unconventional gene silencing "RNA interference"(RNAi). For their discovery of RNAi, Fire and Mello were awarded with the 2006 Nobel Prize in Physiology or Medicine (Zamore 2006). At the same time, plant scientists also found that simultaneous expression of sense and antisense induced more efficient gene silencing in plants (Waterhouse et al. 1998). Re-examination of plant co-suppression, as well as antisense-, or antisense-and-sense mediated plant gene silencing, revealed that all the processes led to the cellular production of dsRNAs. This activated the RNAi pathway, resulting in the observed silencing of homologous endogenous and introduced loci (Hamilton and Baulcombe 1999; Stam et al. 2000; Tang et al. 2003; Van Houdt et al. 2000).

The process of RNAi was dissected biochemically in both plants and animals and shown to be conserved amongst diverse eukaryotes. Zamore and co-investigators empirically showed that small 21-23 nt RNAs, or small interfering RNAs (siRNAs), were the key players in mediating specific RNA degradation in an in vitro Drosophila system (Zamore et al. 2000). siRNAs were predicted and confirmed to be the direct products of dsRNA cleavage by the multi-domain RNase III enzyme termed Dicer (Bass 2000; Bernstein et al. 2001). siRNAs are extremely similar in length to those discovered earlier in virus induced gene silencing (VIGS) in plants (Hamilton and Baulcombe 1999), and indeed, Dicer activity is readily detected in wheat germ and cauliflower extracts (Tang et al. 2003). siRNAs are subsequently assembled into multiprotein complexes, or siRNPs, and then into active RNA induced silencing complexes (RISCs); these seek and cleave siRNA-complementary target mRNAs (Bernstein et al. 2001; Zamore 2006).

An endogenous negative gene regulatory pathway, known as the microRNA (miRNA) pathway, also uses small RNAs of $22 \mathrm{nt}$ in length (Bartel and Bartel 2003;
Bartel 2004; Lai 2003; Palatnik et al. 2003; Reinhart et al. 2002; Tang et al. 2003; Voinnet et al. 2003). miRNAs are universally derived from longer precursor transcripts that adopt a stem-loop structure with a significant, but imperfectly double-stranded character. Dicer is responsible for cleavage of miRNA precursors yielding the mature miRNA (Grishok et al. 2001; Hutvagner et al. 2001; Kim 2005; Lee et al. 2002, 2003; Park et al. 2002; Reinhart et al. 2002). Both siRNAs and miRNAs are assembled into similar RISC structures that regulate complementary RNA targets by targeting them either for cleavage or for translation repression (Hutvagner and Zamore 2002; Llave et al. 2002; Tang 2005; Tang et al. 2003; Xiang and Tang 2006). In plants, most identified miRNAs display extensive or complete complementarity to their presumed target mRNAs, and many of these have been demonstrated to be subject to miRNA-mediated cleavage (Llave et al. 2002; Rhoades et al. 2002; Tang et al. 2003).

The endogenous plant RNA silencing machinery also involves an RNA-directed RNA polymerase (RdRP). RdRP uses RNA templates to synthesize complementary RNAs (cRNAs) in either a primed or non-primed manner (Tang et al. 2003); these anneal to form dsRNAs that are then processed by Dicer to generate siRNAs. Transgenic plants designed to overexpress exogenous or extra copies of endogenous genes often produce aberrant mRNAs with incomplete coding regions. Aberrant RNA species were believed to serve as templates for RdRP, which could mediate their clearance via activation of the RNAi pathway (Wassenegger and Pelissier 1998). But, the requirement for RdRP in plant RNAi can be bypassed by the expression of dsRNA in the form of long inverted-repeat RNA (Beclin et al. 2002), and the RNAi in some animal species, such as Drosophila and human, does not seem to involve RdRP at all by lacking the corresponding genes (Schwarz et al. 2002). Interestingly, RNA silencing can spread over the plants from one region to another, and RdRP has been proposed to play a role in this kind of silencing (Sijen et al. 2001; Vaistij et al. 2002). In addition, plants have multiple members of gene silencing components (Dicer-like enzymes, Augonautes, and RdRPs) (Vaucheret 2006; Xie et al. 2004), which make them a unique system, not only for the study of gene silencing mechanisms, but also for the wide application of gene silencing methods in agriculture.

\section{General approaches to suppress the expression of undesirable genes}

To reduce the levels of undesirable gene products, two general approaches are commonly used: recessive gene disruption and dominant gene silencing. In gene disruption approaches, the target sequence is mutated to eliminate 
either expression or function, whereas dominant gene silencing methods induce either the destruction of the gene transcript or the inhibition of transcription. The advantages of the dominant gene silencing methodologies over the gene disruption approach are 2-fold. First, dominant gene silencing is easier to manipulate genetically and to screen for subsequent transgenic plants. Second, dominant gene silencing can be manipulated in a spatial and temporal manner, using specific promoters. Among the dominant gene silencing approaches, dsRNA triggered RNAi is the most powerful method (Smith et al. 2000); it is the most efficient in terms of the extent of gene silencing and the resulting silencing is almost as complete as in a gene knockout approach. It appears that dsRNA triggered RNAi directly bypasses the requirement for dsRNA synthesis via RdRP, which is likely the rate-limiting step in the plant RNAi pathway.

\section{RNAi silencing technologies and their application in plants}

Although dsRNA-triggered gene silencing was discovered in plants via crossing parents that overexpress sense and antisense RNA by Peter Waterhouse and colleagues (Waterhouse et al. 1998) and in animals by Fire and Mello in 1998 (Fire et al. 1998), the first to apply this technology to plants was Chuang and colleagues in 2000 (Chuang and Meyerowitz 2000). In this case, dsRNAs were produced and triggered efficient silencing of flower identity genes using inverted repeats. This vector-based RNAi technology was further improved, using an intron, instead of a fragment of DNA, as the linker by Peter Waterhouse and colleagues (Smith et al. 2000). These RNAi vectors were specifically designed to generate long dsRNA species with the same sequence as the target genes. Similarly, vectors designed to express hairpin RNAs (hpRNAs) were also successfully applied to silence the corresponding target genes (Wesley et al. 2003). Since constitutive expression of dsRNA or hairpin RNA of some genes often leads to unexpected adverse effects on plant growth and development, chemically inducible RNAi silencing vectors were developed to enable temporal and spatial control of gene silencing (Chen et al. 2003; Guo et al. 2003; Wielopolska et al. 2005). The application of such chemically inducible silencing systems to the study of plant functional genomics is significant, but the large-scale use of chemicals for plant improvement is impractical and harmful to the environment. Tissue- or organ-specific control of gene silencing might be a better choice in developing plant RNAi technologies.

Another approach to silence genes in plants is virusinduced gene silencing (VIGS) (Dinesh-Kumar et al. 2003;
Ratcliff et al. 2001; Zhang and Ghabrial 2006). In VIGS, target genes can be transiently inactivated by infecting a plant with a recombinant virus that expresses pieces of the plant's endogenous gene transcript. In essence, VIGS is a virus-induced RNAi technology without introducing any genetic change in plants. VIGS is very useful for gene functional studies (Ratcliff et al. 2001; Zhang and Ghabrial 2006) but can do nothing to change genetic information for plant improvement.

\section{Strategies for improvement of plant nutritional value and advantages of the RNAi approach}

Genetic engineering technologies have advantages over classical breeding, not only by enlarging the scope of genes and the types of mutations to be manipulated, but also by the ability to control the spatial and temporal expression patterns of the genes of interest. Control of spatial and temporal expression patterns is important because for many crops the tissue that is consumed as food (mostly seeds) is distinct from tissue that controls plant growth and productivity (mainly roots and shoots). However, in many cases genes controlling specific traits do not operate in a tissue-specific manner, but function in all or most plant organs. Therefore, a mutation of a given gene that is good for the improvement of seed quality is often deleterious for the growth of other plant organs.

A well-studied example illustrating such a problem is increasing the level of lysine in plants. Lysine synthesis is strongly regulated by a feedback inhibition loop in which lysine inhibits the activity of dihydrodipicolinate synthase (DHPS), the first enzyme on the pathway specifically committed to lysine biosynthesis. Genetic mutations in the tobacco DHPS gene, rendering its encoded DHPS lysineinsensitive, causes lysine overproduction in all plant organs (Frankard et al. 1992; Negrutiu et al. 1984). However, although high lysine levels in seeds are beneficial, increases in the level of this amino acid in vegetative tissues are undesirable, because high levels of lysine cause abnormal vegetative growth and flower development that, in turn, reduces seed yield (Frankard et al. 1992; Negrutiu et al. 1984). Targeting the expression of bacterial genes encoding lysine-insensitive DHPS to seeds of several transgenic model and crop plants using seed-specific promoters, eliminated its undesirable effects in vegetative tissues, resulting in plants with good growth characteristics and high lysine levels in their seeds (Falco et al. 1995; Karchi et al. 1994; Mazur et al. 1999). This approach has also recently reached commercial application by the approval of a high-lysine maize variety (Mavera ${ }^{\mathrm{TM}}$ ) for animal feeding, developed by Renessen (http://www.renessen.com/men_prod_corn.asp). 
Tissue-specific manipulation in transgenic plants holds importance not only for gene overexpression, but also for gene suppression approaches (Fig. 1). This is because traits of interest in plant organs that are consumed as foods may also be negatively regulated by different genes controlling a variety of factors such as: (i) enzymes that either degrade or convert the desired metabolites into undesirable ones; and (ii) enzymes, or cellular processes, or regulatory factors that interfere with the production of the desired metabolite. Such genes could be suppressed, but their constitutive suppression might have adverse effects on plant growth and reproduction.

To date, the utilization of the RNAi technology to enhance specifically the nutritional value of plant organs that are consumed as foods is progressively increasing, with several published successful efforts, suggesting that this approach has tremendous potential. The first is also associated with improving lysine level in seeds. Because lysine accumulation in plants is negatively affected by its catabolism (degradation), constitutive knockout of lysine catabolism using a gene insertion knockout approach accelerates lysine accumulation in seeds when combined with the seed-specific expression of a feedback-insensitive DHPS (Zhu and Galili 2003). However, seeds of plants that have accumulated elevated lysine levels germinate poorly because the excess lysine levels produced in the seeds are not efficiently degraded during seed germination (Zhu and Galili 2003). Reduction of lysine catabolism specifically during seed development by an RNAi approach indeed improves seed germination (Zhu and Galili 2004).

Seed-specific RNAi approaches have also successfully been used to generate dominant high lysine corn by suppressing the expression of $22-\mathrm{kD}$ maize zein storage proteins, a group of abundant proteins in maize seed but poor in lysine content (Segal et al. 2003). Reduction of lysinepoor zeins by traditional breeding was only successful in screening recessive lysine-rich mutants, called opaque mutants, particularly opaque 2 . Opaque- 2 encodes a maize b-zip type transcriptional factor that controls the expression of a subset of storage proteins including the $22-\mathrm{kD}$ zein storage protein. Albeit rich in lysine, this opaque 2 mutant is not very useful in agriculture because of its other adverse effects on seed quality and yield. Down-regulation of the maize lysine-poor 22-kD zein gene via RNAi does not alter the general functions of the Opaque- 2 transcription factor, but generates quality and normal maize seeds with high levels of lysine-rich proteins and free lysine. Maize is mostly used in western countries for livestock feed, but in many developing countries it is also a staple crop for humans. It is thus expected that high lysine maize, developed using RNAi approaches, will be of significant economical and humanitarian significance world wide and that a similar RNAi-mediated approach will be used to enhance the lysine content in seeds of other staple crops.

Another nutritionally important crop is cotton. Cotton is mainly used for fiber production, and is an important crop not only in developed countries, but also in many developing countries where malnutrition and starvation are widespread (Sunilkumar et al. 2006). In these developing areas, the cottonseeds that remain after fiber extraction could be extensively used as sources of protein and calories, but they are largely underutilized because they contain a toxic gossypol terpenoid. Gossypol is also produced in vegetative cotton tissues where it protects cotton plants from insects and other pathogens (Sunilkumar et al. 2006). Hence, the suppression of its production should occur specifically in cottonseeds. Indeed, transgenic cotton plants expressing a RNAi construct of the $\delta$-cadinene synthase gene of gossypol synthesis fused to a seed-specific promoter caused seed-specific reduction of this metabolite, while its content in non-seed tissues was comparable to the control plants (Sunilkumar et al. 2006). These cotton plants are thus expected to have similar insect and pathogen resistance to that of wild type cotton, but to produce seeds with higher nutritional value.

While insufficient food calories is one of the major causes of malnutrition in developing countries, an excess of digested calories leads to obesity and other diseases in developed countries (Maskarinec et al. 2006). Foods rich in inefficiently digested carbohydrates, such as fiber, are therefore considered to be health promoting (Williams 1995). The major nutritional source of plant-derived carbohydrates is starch, which is composed of amylopectin and amylose polysaccharides, synthesized by two competitive pathways. Yet, in cooked plant foods undergoing cooling before eating, amylose molecules tend to efficiently form digestion-resistant complexes that are part of healthy dietary fiber (Crowe et al. 2000). Aiming to increase the relative content of amylose in wheat grains, a RNAi construct designed to silence the genes encoding the two starch-branching isozymes of amylopectin synthesis, were expressed under a seed-specific promoter in wheat (Regina et al. 2006). This resulted in increased grain amylose content to over $70 \%$ of the total starch content. When fed to rats in a diet as a wholemeal, the high amylose grains had positive effects on indices of gastrointestinal health, elucidating the potential of RNAi technology to improve human health, particularly in developing countries (Regina et al. 2006).

A significant part of human diets both in developed and developing countries is composed of vegetables. Among the vegetables, tomato fruits are relatively rich in a number of vitamins as well other health promoting metabolites, such as flavonoids and carotenoids, including the strong antioxidant carotenoid, or lycopene, which provides the 
tomato fruit with its typical red color. Carotenoids are synthesized by the same biosynthetic pathway that synthesizes chlorophyll, and it has been shown that genes controlling the light-mediated regulation of the photosynthetic machinery also influence tomato fruit quality by altering the levels of carotenoids and flavonoids (AdamsPhillips et al. 2004). The tomato high pigment $(h p-2)$ phenotype, which accumulates elevated levels of carotenoids and flavonoids, is due to mutations in the regulatory gene DE-ETHIOLATEDI (DET1), which represses several light-dependent signaling pathways (Levin et al. 2003; Mustilli et al. 1999). Despite their positive effects on fruit quality, $h p-2$ mutants generally possess abnormal growth and various vegetative phenotypes and so are transgenic plants in which the DETl gene is constitutively silenced (Davuluri et al. 2004; Levin et al. 2003; Mustilli et al. 1999). Such negative phenotypes are not unexpected, taking into account the central regulatory function of the DET1 gene in light signaling and photosynthesis. Yet, RNAi-mediated suppression of DETl expression under fruit-specific promoters has recently shown to improve carotenoid and flavonoid levels in tomato fruits with minimal effects on plant growth and other fruit quality parameters (Davuluri et al. 2005). This exemplifies again how coupling the highly efficient RNAi gene suppression machinery with tissue specific promoters provides a highly valuable trait that is impossible to obtain by conventional breeding.

RNAi technology has also been successful in genetic modification of the fatty acid composition of oil. A hairpin RNA- (hpRNA) mediated RNAi method was used in cotton to down-regulate two key fatty acid desaturase genes encoding stearoyl-acyl-carrier protein $\Delta 9$-desaturase and oleoyl-phosphatidylcholine $\omega 6$-desaturase (Liu et al. 2002). Knockdown of these two genes in cotton led to the increase of nutritionally improved high-oleic (HO) and high-stearic (HS) cottonseed oils that are essential fatty acids for human heart health. It is almost certain that more cases of improved crops via dsRNA-triggered RNAi technology will be reported in the coming years. With more target genes of metabolic pathways discovered in the practice of nutritional genomics (DellaPenna 1999; Grusak 2002), transcriptomics, proteomics, and metabolomics (Bino et al. 2004; Fiehn et al. 2000; Fukusaki and Kobayashi 2005; Hall 2006; Schauer and Fernie 2006) in plants, RNAi and miRNA technologies will become essential tools to manipulate plant macro- and micronutrients for human health. The readers are referred to Larkin and Harrigan (2007) and Wakasa et al. (2007) for examples of the application of metabolic profiling to studying a diverse range of transgenically modified plants. It is evident that metabolic profiling platforms will have value in assessing changes in pathways associated with the production of important nutrients and plant chemicals, including but not restricted to fatty acids, amino acids, carbohydrates, carotenoids, flavonoids and terpenses such as gossypol.

\section{Countersilencing to overexpress valuable genes in plants}

It is generally believed that RNAi originally evolved as a defense mechanism against invasive nucleic acids, including viruses and transposons. For example, most plant RNA viruses form a dsRNA intermediate during viral propagation, which can be cleaved by Dicer to generate siRNAs that will target the viral RNA genome for degradation. A logical counter-defense by many viruses has been to evolve inhibitors of RNAi, which allow them to productively infect plants even in the presence of an active RNAi pathway (Ambros 2001; Kasschau and Carrington 1998; Li and Ding 2006; Llave et al. 2000). This has apparently happened quite often during evolution, and some 20 different RNA silencing suppressors have been identified from different plant viruses in recent years and the number is still increasing.

These RNA silencing suppressors might prove to be not only useful tools for dissecting the biochemical steps of RNAi (Dunoyer et al. 2004; Zamore 2004; Lakatos et al. 2006), but could also be effective in promoting expression of plant transgenes. For example, the p19 protein encoded by tombusviruses was recently found to inhibit RNAi by binding siRNAs with high affinity (Lakatos et al. 2004; Silhavy et al. 2002; Vargason et al. 2003; Ye et al. 2003; Zamore 2004). When the host silencing response was suppressed by p19 in tobacco plants, the expression of a variety of transgenes in a transient expression assay was enhanced by greater than 50-fold (Voinnet et al. 2003). Therefore, transgenic plants expressing p19 or other RNA silencing suppressors should overexpress the desired genes that were so mysteriously suppressed for so long. Quite ironically then, it could be the case that both RNAi and inhibitors of RNAi, themselves the product of host-virus co-evolution, could ultimately be co-opted by people to engineer crops for human benefit. However, viral silencing suppressors could also affect the biogenesis of endogenous miRNAs (Chellappan et al. 2005; Mlotshwa et al. 2005; Silhavy and Burgyan 2004; Yu et al. 2006); this co-option will also depend on fine-tuning expression of the silencing suppressors at a proper developmental stage to avoid their possible interference with endogenous miRNA-programmed normal development. 


\section{The second-generation RNAi vectors: microRNAs}

Current RNAi vectors were designed to produce either short siRNAs such as those produced by animal RNAi vectors, or long dsRNAs by plant RNAi vectors. Animal RNAi vectors generally employ U6 or H1 RNA polymerase III (pol III) promoters to express RNAs with small stem-loop or hairpin structures to silence endogenous genes (Miyagishi and Taira 2002; Sui et al. 2002; Xia et al. 2003). However, long dsRNAs, produced by these RNAi vectors, tend to activate PKR pathways and cause nonspecific cell death in mammalian cells (Bridge et al. 2003; Davis and Watson 1996; Marques and Williams 2005; Robbins and Rossi 2005; Sledz et al. 2003). Plants also express PKR genes and might have a similar pathway that could function as part of the plant stress response (Langland et al. 1995). Avoiding the activation of the PKR pathway in cells remains a major challenge in developing RNAi technology.

By contrast, endogenous expression of extensive microRNAs in plants and animals do not exhibit adverse effects other than their programmed roles in gene regulation for proper development (Ambros 2003; Bartel and Bartel 2003; Palatnik et al. 2003). It appears that the structure of microRNAs has selectively evolved to avoid triggering the PKR pathway. This avoidance is likely due to a structural basis for discriminating self and non-self dsRNA in the cells (Marques et al. 2006; Schlee et al. 2006; Sioud 2006). Developing second-generation RNAi vectors characterized by miRNA structures might provide a safer alternative and more advantages for controlling gene expression for several reasons. First, miRNAs do not trigger the PKR pathway. Second, miRNAs accurately target gene transcripts for destruction or translation repression with high efficiency (Llave et al. 2002; Palatnik et al. 2003; Tang et al. 2003). Human miR30-backbone delivered siRNA was $80 \%$ more effective in reducing the target gene products than siRNA expressed by conventional short hairpin RNA (Boden et al. 2004). Third, miRNA expression is subject to temporal and spatial regulation (Ambros 2001; LagosQuintana et al. 2002; Lau et al. 2001; Reinhart et al. 2002). Dissection of miRNA gene structures will provide extra choices for the development of tissue-specific RNAi vectors. Fourth, one miRNA is able to target several different genes or members of a gene family such as the miR165/166 directed cleavage of $P H V$ and $P B H$ (Rhoades et al. 2002; Tang et al. 2003).

Finally, single-stranded miRNAs are initially generated as siRNA-like duplexes whose structures are highly asymmetrical in energy at the duplex ends (Khvorova et al. 2003; Zamore 2006). These asymmetrical duplex structures predestine one strand to enter the RISC to its maximum, while the other strand is probably destroyed (Zamore
2006). As a result, miRNA-like small RNAs produced by miRNA-based siRNA vectors should display a higher preference for RISC assembly and direct efficient cleavage of their target mRNAs (Tang and Galili 2004).

MiRNA-based vectors have great potential in both plants and animals. Indeed, artificial plant miRNAs have been developed and successfully applied to the silencing of various plant endogenous genes and plant pathogen genes (Alvarez et al. 2006; Du et al. 2006; Epanchintsev et al. 2006; Niu et al. 2006; Schwab et al. 2006; Silva et al. 2005). Web-based miRNA designers have been developed to help design miRNA-like structures for silencing specific genes in plant and animals (http://wmd.weigelworld.org/bin/mirnatools.pl?; http://www.ccts.uky.edu/Research/microRNA/ miRNAResearchHome.aspx). The designing rules were based on the study of extensive miRNA duplex structure and have been proved effective in gene silencing in vitro and in vivo.

\section{Conclusions and perspective}

The nutritional value of human vegetable foods is one of the focuses of plant breeding in agriculture and plays an increasing role in prevention of various human diseases associated with malnutrition. Tremendous efforts have been invested in improving the nutritional value of human plant foods and livestock feeds over the past years. RNAi and miRNA technologies of gene silencing are newly developed genomics tools that have great advantages over antisense and co-suppression due to their higher silencing efficiency and shortened time period for screening for the targeted plants. These technologies are particularly useful in conjunction with the practice of gene or pathway discoveries through nutritional genomics, trancriptomics, proteomics, and metabolomics in plants to improve human health.

Tissue or organ-specific RNAi vectors have recently been proven to be useful for targeted gene silencing in specific plant tissues and organs with minimal interference with the normal plant life cycle. New-generation RNAi vectors, the miRNA vectors have been developed with high silencing accuracy and fewer side effects in plants. Genetic engineering of highly nutritional food crops requires both gene silencing and counter-silencing technologies. Developing vectors that can suppress the RNAi pathway but overexpress transgenes in a tissue-specific manner will revolutionize this field. Such vectors could be based on various viral RNA silencing suppressors and their derivatives. Future directions will focus on developing finely tuned RNAi-based gene silencing vectors that are able to operate in a temporally and spatially controlled manner. 
Acknowledgements G.T. is supported by the KTRDC and the USDA-NRI Grants 2006-35301-17115 and 2006-35100-17433; G.G. is an incumbent of the Bronfman Chair of Plant Sciences with studies of plant nutrition supported by grants from BARD (Binational IsraelUSA Science Foundation), the Israel Academy of Sciences and Humanities, National Council for Research and Development, DIP (German-Israeli Foundation), and the Framework Program of the Commission of the European Communities.

\section{References}

Adams-Phillips, L., Barry, C., \& Giovannoni, J. (2004). Signal transduction systems regulating fruit ripening. Trends in Plant Science, 9, 331-338.

Aharoni, A., Ric de Vos, C. H., Verhoeven, H. A., Maliepaard, C. A., Kruppa, G., Bino, R., \& Goodenowe, D. B. (2002). Nontargeted metabolome analysis by use of Fourier transform ion cyclotron mass spectrometry. Omics, 6, 217-234.

Alvarez, J. P., Pekker, I., Goldshmidt, A., Blum, E., Amsellem, Z., \& Eshed, Y. (2006). Endogenous and synthetic microRNAs stimulate simultaneous, efficient, and localized regulation of multiple targets in diverse species. Plant Cell, 18, 1134-1151.

Ambros, V. (2001). microRNAs: Tiny regulators with great potential. Cell, 107, 823-826.

Ambros, V. (2003). MicroRNA pathways in flies and worms: Growth, death, fat, stress, and timing. Cell, 113, 673-676.

Bartel, D. P. (2004). MicroRNAs: Genomics, biogenesis, mechanism, and function. Cell, 116, 281-297.

Bartel, B., \& Bartel, D. P. (2003). MicroRNAs: At the root of plant development? Plant Physiology, 132, 709-717.

Bass, B. L. (2000). Double-stranded RNA as a template for gene silencing. Cell, 101, 235-238.

Beclin, C., Boutet, S., Waterhouse, P., \& Vaucheret, H. (2002). A branched pathway for transgene-induced RNA silencing in plants. Current Biology, 12, 684-688.

Bederman, I. R., Kasumov, T., Reszko, A. E., David, F., Brunengraber, H., \& Kelleher, J. K. (2004a). In vitro modeling of fatty acid synthesis under conditions simulating the zonation of lipogenic [13C]acetyl-CoA enrichment in the liver. The Journal of Biological Chemistry, 279, 43217-43226.

Bederman, I. R., Reszko, A. E., Kasumov, T., David, F., Wasserman, D. H., Kelleher, J. K., \& Brunengraber, H. (2004b). Zonation of labeling of lipogenic acetyl-CoA across the liver: Implications for studies of lipogenesis by mass isotopomer analysis. The Journal of Biological Chemistry, 279, 43207-43216.

Bernstein, E., Caudy, A. A., Hammond, S. M., \& Hannon, G. J. (2001). Role for a bidentate ribonuclease in the initiation step of RNA interference. Nature, 409, 363-366.

Bino, R. J., Hall, R. D., Fiehn, O., Kopka, J., Saito, K., Draper, J., Nikolau, B. J., Mendes, P., Roessner-Tunali, U., Beale, M. H., et al. (2004). Potential of metabolomics as a functional genomics tool. Trends in Plant Science, 9, 418-425.

Boden, D., Pusch, O., Silbermann, R., Lee, F., Tucker, L., \& Ramratnam, B. (2004). Enhanced gene silencing of HIV-1 specific siRNA using microRNA designed hairpins. Nucleic Acids Research, 32, 1154-1158.

Boros, L. G. (2005). Metabolic targeted therapy of cancer: Current tracer technologies and future drug design strategies in the old metabolic network. Metabolomics, 1, 11-15.

Bridge, A. J., Pebernard, S., Ducraux, A., Nicoulaz, A. L., \& Iggo, R. (2003). Induction of an interferon response by RNAi vectors in mammalian cells. Nature Genetics, 34, 263-264.

Buchholz, A., Takors, R., \& Wandrey, C. (2001). Quantification of intracellular metabolites in Escherichia coli K12 using liquid chromatographic-electrospray ionization tandem mass spectrometric techniques. Analytical Biochemistry, 295, 129-137.

Chellappan, P., Vanitharani, R., \& Fauquet, C. M. (2005). MicroRNA-binding viral protein interferes with Arabidopsis development. Proceedings of the National Academy of Sciences of the USA, 102, 10381-10386.

Chen, S., Hofius, D., Sonnewald, U., \& Bornke, F. (2003). Temporal and spatial control of gene silencing in transgenic plants by inducible expression of double-stranded RNA. Plant Journal, 36, 731-740.

Chuang, C. F., \& Meyerowitz, E. M. (2000). Specific and heritable genetic interference by double-stranded RNA in Arabidopsis thaliana. Proceedings of the National Academy of Sciences of the USA, 97, 4985-4990.

Crowe, T. C., Seligman, S. A., \& Copeland, L. (2000). Inhibition of enzymic digestion of amylose by free fatty acids in vitro contributes to resistant starch formation. Journal of Nutrition, 130, 2006-2008.

Davies, W. P. (2003). An historical perspective from the Green Revolution to the gene revolution. Nutrition Reviews, 61, S124S134.

Davis, S., \& Watson, J. C. (1996). In vitro activation of the interferoninduced, double-stranded RNA-dependent protein kinase PKR by RNA from the $3^{\prime}$ untranslated regions of human alphatropomyosin. Proceedings of the National Academy of Sciences of the USA, 93, 508-513.

Davuluri, G. R., van Tuinen, A., Fraser, P. D., Manfredonia, A., Newman, R., Burgess, D., Brummell, D. A., King, S. R., Palys, J., Uhlig, J., et al. (2005). Fruit-specific RNAi-mediated suppression of DET1 enhances carotenoid and flavonoid content in tomatoes. Nature Biotechnology, 23, 890-895.

Davuluri, G. R., van Tuinen, A., Mustilli, A. C., Manfredonia, A., Newman, R., Burgess, D., Brummell, D. A., King, S. R., Palys, J., Uhlig, J., et al. (2004). Manipulation of DET1 expression in tomato results in photomorphogenic phenotypes caused by posttranscriptional gene silencing. Plant Journal, 40, 344-354.

DellaPenna, D. (1999). Nutritional genomics: Manipulating plant micronutrients to improve human health. Science, 285, 375-379.

Dinesh-Kumar, S. P., Anandalakshmi, R., Marathe, R., Schiff, M., \& Liu, Y. (2003). Virus-induced gene silencing. Methods in Molecular Biology, 236, 287-294.

Du, G., Yonekubo, J., Zeng, Y., Osisami, M., \& Frohman, M. A. (2006). Design of expression vectors for RNA interference based on miRNAs and RNA splicing. FEBS Journal, 273, 54215427.

Dunoyer, P., Lecellier, C. H., Parizotto, E. A., Himber, C., \& Voinnet, O. (2004). Probing the microRNA and small interfering RNA pathways with virus-encoded suppressors of RNA silencing. Plant Cell, 16, 1235-1250.

Epanchintsev, A., Jung, P., Menssen, A., \& Hermeking, H. (2006). Inducible microRNA expression by an all-in-one episomal vector system. Nucleic Acids Research, 34, e119.

Facchini, P. J., Huber-Allanach, K. L., \& Tari, L. W. (2000). Plant aromatic L-amino acid decarboxylases: Evolution, biochemistry, regulation, and metabolic engineering applications. Phytochemistry, 54, 121-138.

Falco, S. C., Guida, T., Locke, M., Mauvais, J., Sanders, C., Ward, R. T., \& Webber, P. (1995). Transgenic canola and soybean seeds with increased lysine. Biotechnology (NY), 13, 577-582.

Fiehn, O. (2002). Metabolomics - the link between genotype and phenotype. Plant Molecular Biology, 48, 155-171.

Fiehn, O., Kopka, J., Dormann, P., Altmann, T., Trethewey, R. N., \& Willmitzer, L. (2000). Metabolite profiling for plant functional genomics. Nature Biotechnology, 18, 1157-1161.

Fire, A., Xu, S., Montgomery, M. K., Kostas, S. A., Driver, S. E., \& Mello, C. C. (1998). Potent and specific genetic interference by 
double-stranded RNA in Caenorhabditis elegans. Nature, 391, 806-811.

Frankard, V., Ghislain, M., \& Jacobs, M. (1992). Two feedbackinsensitive enzymes of the aspartate pathway in Nicotiana sylvestris. Plant Physiology, 99, 1285-1293.

Fukusaki, E., \& Kobayashi, A. (2005). Plant metabolomics: Potential for practical operation. Journal of Bioscience and Bioengineering, 100, 347-354.

Galili, G., Galili, S., Lewinsohn, E., \& Tadmor, Y. (2002). Genetic, molecular and genomic approaches to improve the value of plant foods and feeds. Critical Reviews in Plant Sciences, 21, 167-204.

Gamache, P. H., Meyer, D. F., Granger, M. C., \& Acworth, I. N. (2004). Metabolomic applications of electrochemistry/mass spectrometry. Journal of the American Society for Mass Spectrometry, 15, 1717-1726.

Goodacre, R., Vaidyanathan, S., Dunn, W. B., Harrigan, G. G., \& Kell, D. B. (2004). Metabolomics by numbers: Acquiring and understanding global metabolite data. Trends in Biotechnology, 22, 245-252.

Grishok, A., Pasquinelli, A. E., Conte, D., Li, N., Parrish, S., Ha, I., Baillie, D. L., Fire, A., Ruvkun, G., \& Mello, C. C. (2001). Genes and mechanisms related to RNA interference regulate expression of the small temporal RNAs that control C. elegans developmental timing. Cell, 106, 23-34.

Grusak, M. A. (2002). Phytochemicals in plants: Genomics-assisted plant improvement for nutritional and health benefits. Current Opinion in Biotechnology, 13, 508-511.

Guo, H. S., Fei, J. F., Xie, Q., \& Chua, N. H. (2003). A chemicalregulated inducible RNAi system in plants. Plant Journal, 34, 383-392.

Hall, R. D. (2006). Plant metabolomics: From holistic hope, to hype, to hot topic. The New Phytologist, 169, 453-468.

Hamilton, A. J., \& Baulcombe, D. C. (1999). A species of small antisense RNA in posttranscriptional gene silencing in plants. Science, 286, 950-952.

Hannon, G. J. (2002). RNA interference. Nature, 418, 244-251.

Harrigan, G. G., LaPlante, R. H., Cosma, G. N., Cockerell, G., Goodacre, R., Maddox, J. F., Luyendyk, J. P., Ganey, P. E., \& Roth, R. A. (2004). Application of high-throughput Fouriertransform infrared spectroscopy in toxicology studies: Contribution to a study on the development of an animal model for idiosyncratic toxicity. Toxicology Letters, 146, 197-205.

Hoisington, D., Khairallah, M., Reeves, T., Ribaut, J. M., Skovmand, B., Taba, S., \& Warburton, M. (1999). Plant genetic resources: What can they contribute toward increased crop productivity? Proceedings of the National Academy of Sciences of the USA, 96, 5937-5943.

Hollywood, K., Brison, D. R., \& Goodacre, R. (2006). Metabolomics: Current technologies and future trends. Proteomics, 6 , 4716-4723.

Hughes, E. H., \& Shanks, J. V. (2002). Metabolic engineering of plants for alkaloid production. Metabolic Engineering, 4, 41-48.

Hutvagner, G., McLachlan, J., Pasquinelli, A. E., Balint, E., Tuschl, T., \& Zamore, P. D. (2001). A cellular function for the RNAinterference enzyme Dicer in the maturation of the let-7 small temporal RNA. Science, 293, 834-838.

Hutvagner, G., \& Zamore, P. D. (2002). A microRNA in a multipleturnover RNAi enzyme complex. Science, 297, 2056-2060.

Karchi, H., Shaul, O., \& Galili, G. (1994). Lysine synthesis and catabolism are coordinately regulated during tobacco seed development. Proceedings of the National Academy of Sciences of the USA, 91, 2577-2581.

Kasschau, K. D., \& Carrington, J. C. (1998). A counterdefensive strategy of plant viruses: Suppression of posttranscriptional gene silencing. Cell, 95, 461-470.
Khvorova, A., Reynolds, A., \& Jayasena, S. D. (2003). Functional siRNAs and miRNAs exhibit strand bias. Cell, 115, 209-216.

Kim, V. N. (2005). MicroRNA biogenesis: Coordinated cropping and dicing. Nature Reviews Molecular Cell Biology, 6, 376-385.

Kutchan, T. M. (2005). Predictive metabolic engineering in plants: Still full of surprises. Trends in Biotechnology, 23, 381-383; discussion 383-384.

Lagos-Quintana, M., Rauhut, R., Yalcin, A., Meyer, J., Lendeckel, W., \& Tuschl, T. (2002). Identification of tissue-specific microRNAs from mouse. Current Biology, 12, 735-739.

Lai, E. C. (2003). microRNAs: Runts of the genome assert themselves. Current Biology, 13, R925-R936.

Lakatos, L., Csorba, T., Pantaleo, V., Chapman, E. J., Carrington, J. C., Liu, Y. P., Dolja, V. V., Calvino, L. F., Lopez-Moya, J. J., \& Burgyan, J. (2006). Small RNA binding is a common strategy to suppress RNA silencing by several viral suppressors. EMBO Journal, 25, 2768-2780.

Lakatos, L., Szittya, G., Silhavy, D., \& Burgyan, J. (2004). Molecular mechanism of RNA silencing suppression mediated by 19 protein of tombusviruses. EMBO Journal, 23, 876-884.

Langland, J. O., Jin, S., Jacobs, B. L., \& Roth, D. A. (1995). Identification of a plant-encoded analog of PKR, the mammalian double-stranded RNA-dependent protein kinase. Plant Physiology, 108, 1259-1267.

Larkin, P. J., \& Harrigan, G. G. (2007). Opportunities and surprises in crops modified by transgenic technology: Metabolic engineering of benzylisoquinoline alkaloid, gossypol and lysine biosynthetic pathways. Metabolomics, 3 (this issue).

Lau, N. C., Lim, L. P., Weinstein, E. G., \& Bartel, D. P. (2001). An abundant class of tiny RNAs with probable regulatory roles in Caenorhabditis elegans. Science, 294, 858-862.

Lee, M. (1998). Genome projects and gene pools: New germplasm for plant breeding? Proceedings of the National Academy of Sciences of the USA, 95, 2001-2004.

Lee, Y., Ahn, C., Han, J., Choi, H., Kim, J., Yim, J., Lee, J., Provost, P., Radmark, O., Kim, S., et al. (2003). The nuclear RNase III Drosha initiates microRNA processing. Nature, 425, 415-419.

Lee, Y., Jeon, K., Lee, J. T., Kim, S., \& Kim, V. N. (2002). MicroRNA maturation: Stepwise processing and subcellular localization. EMBO Journal, 21, 4663-4670.

Levin, I., Frankel, P., Gilboa, N., Tanny, S., \& Lalazar, A. (2003). The tomato dark green mutation is a novel allele of the tomato homolog of the DEETIOLATED1 gene. Theoretical and Applied Genetics, 106, 454-460.

Lewis, B. P., Burge, C. B., \& Bartel, D. P. (2005). Conserved seed pairing, often flanked by adenosines, indicates that thousands of human genes are microRNA targets. Cell, 120, 15-20.

Li, F., \& Ding, S. W. (2006). Virus counterdefense: Diverse strategies for evading the RNA-silencing immunity. Annual Review of Microbiology, 60, 503-531.

Liu, Q., Singh, S. P., \& Green, A. G. (2002). High-stearic and higholeic cottonseed oils produced by hairpin RNA-mediated posttranscriptional gene silencing. Plant Physiology, 129, 17321743.

Llave, C., Kasschau, K. D., \& Carrington, J. C. (2000). Virus-encoded suppressor of posttranscriptional gene silencing targets a maintenance step in the silencing pathway. Proceedings of the National Academy of Sciences of the USA, 97, 13401-13406.

Llave, C., Xie, Z., Kasschau, K. D., \& Carrington, J. C. (2002). Cleavage of Scarecrow-like mRNA targets directed by a class of Arabidopsis miRNA. Science, 297, 2053-2056.

Marques, J. T., Devosse, T., Wang, D., Zamanian-Daryoush, M., Serbinowski, P., Hartmann, R., Fujita, T., Behlke, M. A., \& Williams, B. R. (2006). A structural basis for discriminating between self and nonself double-stranded RNAs in mammalian cells. Nature Biotechnology, 24, 559-565. 
Marques, J. T., \& Williams, B. R. (2005). Activation of the mammalian immune system by siRNAs. Nature Biotechnology, 23, 1399-1405.

Maskarinec, G., Takata, Y., Pagano, I., Carlin, L., Goodman, M. T., Le Marchand, L., Nomura, A. M., Wilkens, L. R., \& Kolonel, L. N. (2006). Trends and dietary determinants of overweight and obesity in a multiethnic population. Obesity (Silver Spring), 14, $717-726$.

Mazur, B., Krebbers, E., \& Tingey, S. (1999). Gene discovery and product development for grain quality traits. Science, 285, 372375 .

Miyagishi, M., \& Taira, K. (2002). Development and application of siRNA expression vector. Nucleic Acids Research Supplement, $113-114$.

Mlotshwa, S., Schauer, S. E., Smith, T. H., Mallory, A. C., Herr, J. M., Jr., Roth, B., Merchant, D. S., Ray, A., Bowman, L. H., \& Vance, V. B. (2005). Ectopic DICER-LIKE1 expression in P1/ HC-Pro Arabidopsis rescues phenotypic anomalies but not defects in microRNA and silencing pathways. Plant Cell, 17, 2873-2885.

Montgomery, M. K., \& Fire, A. (1998). Double-stranded RNA as a mediator in sequence-specific genetic silencing and co-suppression. Trends in Genetics, 14, 255-258.

Mustilli, A. C., Fenzi, F., Ciliento, R., Alfano, F., \& Bowler, C. (1999). Phenotype of the tomato high pigment-2 mutant is caused by a mutation in the tomato homolog of DEETIOLATED1. Plant Cell, 11, 145-157.

Napoli, C., Lemieux, C., \& Jorgensen, R. (1990). Introduction of a chimeric chalcone synthase gene into petunia results in reversible co-suppression of homologous genes in trans. Plant Cell, 2, 279-289.

Negrutiu, I., Cattoir-Reynearts, A., Verbruggen, I., \& Jacobs, M. (1984). Lysine overproducer mutants with an altered dihydrodipicolinate synthase from protoplast culture of Nicotiana sylvestris (Spegazzini and Comes). TAG Theoretical and Applied Genetics, V68, 11-20.

Nicholson, J. K., Lindon, J. C., \& Holmes, E. (1999). 'Metabonomics': Understanding the metabolic responses of living systems to pathophysiological stimuli via multivariate statistical analysis of biological NMR spectroscopic data. Xenobiotica, 29, 11811189.

Niu, Q. W., Lin, S. S., Reyes, J. L., Chen, K. C., Wu, H. W., Yeh, S. D., \& Chua, N. H. (2006). Expression of artificial microRNAs in transgenic Arabidopsis thaliana confers virus resistance. Nature Biotechnology, 24, 1420-1428.

Oliver, S. G., Winson, M. K., Kell, D. B., \& Baganz, F. (1998). Systematic functional analysis of the yeast genome. Trends in Biotechnology, 16, 373-378.

Palatnik, J. F., Allen, E., Wu, X., Schommer, C., Schwab, R., Carrington, J. C., \& Weigel, D. (2003). Control of leaf morphogenesis by microRNAs. Nature, 425, 257-263.

Park, W., Li, J., Song, R., Messing, J., \& Chen, X. (2002). CARPEL FACTORY, a Dicer homolog, and HEN1, a novel protein, act in microRNA metabolism in Arabidopsis thaliana. Current Biology, 12, 1484-1495.

Raamsdonk, L. M., Teusink, B., Broadhurst, D., Zhang, N., Hayes, A., Walsh, M. C., Berden, J. A., Brindle, K. M., Kell, D. B., Rowland, J. J., et al. (2001). A functional genomics strategy that uses metabolome data to reveal the phenotype of silent mutations. Nature Biotechnology, 19, 45-50.

Ratcliff, F., Martin-Hernandez, A. M., \& Baulcombe, D. C. (2001). Technical advance. Tobacco rattle virus as a vector for analysis of gene function by silencing. Plant Journal, 25, 237-245.

Ratcliffe, R. G., \& Schachar-Hill, Y. (2006). Measuring multiple fluxes through plant metabolic networks. Plant Journal, 45, 490-511.
Regina, A., Bird, A., Topping, D., Bowden, S., Freeman, J., Barsby, T., Kosar-Hashemi, B., Li, Z., Rahman, S., \& Morell, M. (2006). High-amylose wheat generated by RNA interference improves indices of large-bowel health in rats. Proceedings of the National Academy of Sciences of the USA, 103, 3546-3551.

Reinhart, B. J., Weinstein, E. G., Rhoades, M. W., Bartel, B., \& Bartel, D. P. (2002). MicroRNAs in plants. Genes \& Development, 16, 1616-1626.

Rhoades, M. W., Reinhart, B. J., Lim, L. P., Burge, C. B., Bartel, B., \& Bartel, D. P. (2002). Prediction of plant microRNA targets. Cell, 110, 513-520.

Robbins, M. A., \& Rossi, J. J. (2005). Sensing the danger in RNA. Nature Medicine, 11, 250-251.

Schauer, N., \& Fernie, A. R. (2006). Plant metabolomics: Towards biological function and mechanism. Trends in Plant Science, 11, $508-516$

Schlee, M., Hornung, V., \& Hartmann, G. (2006). siRNA and isRNA: Two edges of one sword. Molecular Therapy, 14, 463-470.

Schwab, R., Ossowski, S., Riester, M., Warthmann, N., \& Weigel, D. (2006). Highly specific gene silencing by artificial microRNAs in Arabidopsis. Plant Cell, 18, 1121-1133.

Schwarz, D. S., Hutvagner, G., Haley, B., \& Zamore, P. D. (2002). Evidence that siRNAs function as guides, not primers, in the Drosophila and human RNAi pathways. Molecular Cell, 10, 537-548.

Segal, G., Song, R., \& Messing, J. (2003). A new opaque variant of maize by a single dominant RNA-interference-inducing transgene. Genetics, 165, 387-397.

Shi, Y. (2003). Mammalian RNAi for the masses. Trends in Genetics, $19,9-12$.

Sijen, T., Fleenor, J., Simmer, F., Thijssen, K. L., Parrish, S., Timmons, L., Plasterk, R. H., \& Fire, A. (2001). On the role of RNA amplification in dsRNA-triggered gene silencing. Cell, 107, 465-476.

Silhavy, D., \& Burgyan, J. (2004). Effects and side-effects of viral RNA silencing suppressors on short RNAs. Trends in Plant Science, 9, 76-83.

Silhavy, D., Molnar, A., Lucioli, A., Szittya, G., Hornyik, C., Tavazza, M., \& Burgyan, J. (2002). A viral protein suppresses RNA silencing and binds silencing-generated, 21- to 25-nucleotide double-stranded RNAs. EMBO Journal, 21, 3070-3080.

Silva, J. M., Li, M. Z., Chang, K., Ge, W., Golding, M. C., Rickles, R. J., Siolas, D., Hu, G., Paddison, P. J., Schlabach, M. R., et al. (2005). Second-generation shRNA libraries covering the mouse and human genomes. Nature Genetics, 37, 1281-1288.

Sioud, M. (2006). RNA interference below the immune radar. Nature Biotechnology, 24, 521-522.

Sledz, C. A., Holko, M., de Veer, M. J., Silverman, R. H., \& Williams, B. R. (2003). Activation of the interferon system by short-interfering RNAs. Nature Cell Biology, 5, 834-839.

Smith, N. A., Singh, S. P., Wang, M. B., Stoutjesdijk, P. A., Green, A. G., \& Waterhouse, P. M. (2000). Total silencing by intronspliced hairpin RNAs. Nature, 407, 319-320.

Soga, T., Ueno, Y., Naraoka, H., Ohashi, Y., Tomita, M., \& Nishioka, T. (2002). Simultaneous determination of anionic intermediates for Bacillus subtilis metabolic pathways by capillary electrophoresis electrospray ionization mass spectrometry. Analytical Chemistry, 74, 2233-2239.

Stam, M., de Bruin, R., van Blokland, R., van der Hoorn, R. A., Mol, J. N., \& Kooter, J. M. (2000). Distinct features of posttranscriptional gene silencing by antisense transgenes in single copy and inverted T-DNA repeat loci. Plant Journal, 21, 27-42.

Sui, G., Soohoo, C., Affar el, B., Gay, F., Shi, Y., Forrester, W. C., \& Shi, Y. (2002). A DNA vector-based RNAi technology to suppress gene expression in mammalian cells. Proceedings of the National Academy of Sciences of the USA, 99, 5515-5520. 
Sunilkumar, G., Campbell, L. M., Puckhaber, L., Stipanovic, R. D., \& Rathore, K. S. (2006). Engineering cottonseed for use in human nutrition by tissue-specific reduction of toxic gossypol. Proceedings of the National Academy of Sciences of the USA, 103, 18054-18059.

Tabara, H., Grishok, A., \& Mello, C. C. (1998). RNAi in C. elegans: Soaking in the genome sequence. Science, 282, 430-431.

Tang, G. (2005). siRNA and miRNA: An insight into RISCs. Trends in Biochemical Sciences, 30, 106-114.

Tang, G., \& Galili, G. (2004). Using RNAi to improve plant nutritional value: From mechanism to application. Trends in Biotechnology, 22, 463-469.

Tang, G., Reinhart, B. J., Bartel, D. P., \& Zamore, P. D. (2003). A biochemical framework for RNA silencing in plants. Genes Development, 17, 49-63.

ter Kuile, B. H., \& Westerhoff, H. V. (2001). Transcriptome meets metabolome: Hierarchical and metabolic regulation of the glycolytic pathway. FEBS Letters, 500, 169-171.

Tolstikov, V. V., Lommen, A., Nakanishi, K., Tanaka, N., \& Fiehn, O. (2003). Monolithic silica-based capillary reversed-phase liquid chromatography/electrospray mass spectrometry for plant metabolomics. Analytical Chemistry, 75, 6737-6740.

Trethewey, R. N. (2004). Metabolite profiling as an aid to metabolic engineering in plants. Current Opinion in Plant Biology, 7, 196201.

Vaidyanathan, S., Jones, D., Broadhurst, D., Ellis, J., Jenkins, T., Dunn, W., Hayes, A., Burton, N., Oliver, S., Kell, D., et al. (2005). A laser desorption ionisation mass spectrometry approach for high throughput metabolomics. Metabolomics, 1 , 243-250.

Vaidyanathan, S., Kell, D. B., \& Goodacre, R. (2002). Flow-injection electrospray ionization mass spectrometry of crude cell extracts for high-throughput bacterial identification. Journal of the American Society for Mass Spectrometry, 13, 118-128.

Vaistij, F. E., Jones, L., \& Baulcombe, D. C. (2002). Spreading of RNA targeting and DNA methylation in RNA silencing requires transcription of the target gene and a putative RNA-dependent RNA polymerase. Plant Cell, 14, 857-867.

Van der Krol, A. R., Mur, L. A., Beld, M., Mol, J. N., \& Stuitje, A. R. (1990). Flavonoid genes in petunia: Addition of a limited number of gene copies may lead to a suppression of gene expression. Plant Cell, 2, 291-299.

Van Houdt, H., Van Montagu, M., \& Depicker, A. (2000). Both sense and antisense RNAs are targets for the sense transgene-induced posttranscriptional silencing mechanism. Molecular \& General Genetics, 263, 995-1002.

Vargason, J. M., Szittya, G., Burgyan, J., \& Tanaka Hall, T. M. (2003). Size selective recognition of siRNA by an RNA silencing suppressor. Cell, 115, 799-811.

Vaucheret, H. (2006). Post-transcriptional small RNA pathways in plants: Mechanisms and regulations. Genes Development, 20, 759-771.

Vaucheret, H., Beclin, C., \& Fagard, M. (2001). Post-transcriptional gene silencing in plants. Journal of Cell Science, 114, 30833091.

Villas-Boas, S. G., Mas, S., Akesson, M., Smedsgaard, J., \& Nielsen, J. (2005). Mass spectrometry in metabolome analysis. Mass Spectrometry Reviews, 24, 613-646.

Voinnet, O., Rivas, S., Mestre, P., \& Baulcombe, D. (2003). An enhanced transient expression system in plants based on suppression of gene silencing by the p19 protein of tomato bushy stunt virus. Plant Journal, 33, 949-956.

Wakasa, K., Ishihara, A., Matsuda, F., \& Miyagawa, H. (2007). Metabolomics for metabolically-manipulated plants-effects of deregulated tryptophan synthesis. Metabolomics, 3 (this issue).
Wassenegger, M., \& Pelissier, T. (1998). A model for RNA-mediated gene silencing in higher plants. Plant Molecular Biology, 37, 349-362.

Waterhouse, P. M., Graham, M. W., \& Wang, M. B. (1998). Virus resistance and gene silencing in plants can be induced by simultaneous expression of sense and antisense RNA. Proceedings of the National Academy of Sciences of the USA, 95, 1395913964.

Weckwerth, W., \& Morgenthal, K. (2005). Metabolomics: From pattern recognition to biological interpretation. Drug Discovery Today, 10, 1551-1558.

Welthagen, W., Shellie, R., Spranger, J., Ristow, M., Zimmermann, R., \& Fiehn, O. (2005). Comprehensive two-dimensional gas chromatography-time-of-flight mass spectrometry $(\mathrm{GC} \times \mathrm{GC}$ TOF) for high resolution metabolomics: Biomarker discovery on spleen tissue extracts of obese NZO compared to lean C57BL/6 mice. Metabolomics, 1, 65-73.

Wesley, S. V., Liu, Q., Wielopolska, A., Ellacott, G., Smith, N., Singh, S., \& Helliwell, C. (2003). Custom knock-outs with hairpin RNA-mediated gene silencing. Methods in Molecular Biology, 236, 273-286.

Wielopolska, A., Townley, H., Moore, I., Waterhouse, P., \& Helliwell, C. (2005). A high-throughput inducible RNAi vector for plants. Plant Biotechnology Journal, 3, 583-590.

Williams, C. L. (1995). Importance of dietary fiber in childhood. Journal of the American Dietetic Association, 95, 1140-1146, 1149; quiz 1147-1148.

Wilson, I. D., Plumb, R., Granger, J., Major, H., Williams, R., \& Lenz, E. M. (2005). HPLC-MS-based methods for the study of metabonomics. Journal of Chromatography, 817, 67-76.

Xia, X. G., Zhou, H., Ding, H., Affar el, B., Shi, Y., \& Xu, Z. (2003). An enhanced U6 promoter for synthesis of short hairpin RNA. Nucleic Acids Research, 31, e100.

Xiang, Y., \& Tang, G. (2006). In: N. J. Clarke \& P. Sanseau (Eds.), RISC biology. "microRNA: Biology, function and expression". DNA Press.

Xie, X., Lu, J., Kulbokas, E. J., Golub, T. R., Mootha, V., LindbladToh, K., Lander, E. S., \& Kellis, M. (2005). Systematic discovery of regulatory motifs in human promoters and $3^{\prime}$ UTRs by comparison of several mammals. Nature, 434, 338345.

Xie, Z., Johansen, L. K., Gustafson, A. M., Kasschau, K. D., Lellis, A. D., Zilberman, D., Jacobsen, S. E., \& Carrington, J. C. (2004). Genetic and functional diversification of small RNA pathways in plants. PLoS Biology, 2, E104.

Ye, K., Malinina, L., \& Patel, D. J. (2003). Recognition of small interfering RNA by a viral suppressor of RNA silencing. Nature, 426, 874-878.

Yu, B., Chapman, E. J., Yang, Z., Carrington, J. C., \& Chen, X. (2006). Transgenically expressed viral RNA silencing suppressors interfere with microRNA methylation in Arabidopsis. FEBS Letters, 580, 3117-3120.

Zamore, P. D. (2001). RNA interference: Listening to the sound of silence. Nature Structural Biology, 8, 746-750.

Zamore, P. D. (2004). Plant RNAi: How a viral silencing suppressor inactivates siRNA. Current Biology, 14, R198-R200.

Zamore, P. D. (2006). RNA interference: Big applause for silencing in stockholm. Cell, 127, 1083-1086.

Zamore, P. D., Tuschl, T., Sharp, P. A., \& Bartel, D. P. (2000). RNAi: Double-stranded RNA directs the ATP-dependent cleavage of mRNA at 21 to 23 nucleotide intervals. Cell, 101, 25-33.

Zhang, C., \& Ghabrial, S. A. (2006). Development of Bean pod mottle virus-based vectors for stable protein expression and sequence-specific virus-induced gene silencing in soybean. Virology, 344, 401-411. 
Zhu, X., \& Galili, G. (2003). Increased lysine synthesis coupled with a knockout of its catabolism synergistically boosts lysine content and also transregulates the metabolism of other amino acids in Arabidopsis seeds. Plant Cell, 15, 845-853.
Zhu, X., \& Galili, G. (2004). Lysine metabolism is concurrently regulated by synthesis and catabolism in both reproductive and vegetative tissues. Plant Physiology, 135, 129-136. 